\title{
Moisture sorption characteristics of pistachio
}

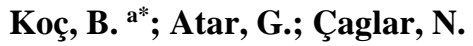

${ }^{\text {a }}$ Gaziantep University, Faculty of Fine Arts, Department of Gastronomy and Culinary Arts, Gaziantep, Turkey

*kocbanu@gmail.com

\begin{abstract}
In this study, the moisture adsorption isotherm of pistachio was determined at $25^{\circ} \mathrm{C}$ and relative humidity (10-90\%), using the standard static, gravimetric method. Eleven sorption models were tested to fit the experimental data. A nonlinear regression analysis method was used to evaluate the constants of the sorption equations. The GAB equation gave the best fit to the experimental data for a wide range of water activity, while BET gave the best fit for a water activity range of 0.1-0.5. The agreement between experimental and predicted values of these models was found to be satisfactory.
\end{abstract}

Keywords: Moisture adsorption isotherm; Sorption model; Pistachio 


\section{Introduction}

Pistachios are one of the oldest edible nuts known to mankind, which are originated from Asia Minor, and are cultivated from Pakistan to Greece and even Italy and U.S.A. But pistachios originated from Gaziantep Region of Turkey, are worldwide known with its high quality and rich distinctive flavor. Pistachios are subjected to various processes after they are harvested. Proper harvesting and postharvest handling are two key activities in achieving maximum yield of good quality pistachio nuts, which effect marketability and profit. Process steps may vary with respect to desired product. For consuption as snack, processing of the nuts includes dehulling, washing, drying to $60-80 \mathrm{~g} / \mathrm{kg}$ moisture (related to whole kernel) in dryers at $65^{\circ} \mathrm{C}$ for 6 to $7 \mathrm{~h}$ or by sun-drying for 3 to $4 \mathrm{~d}$, salting by immersion in $100 \mathrm{~g} / \mathrm{kg}$ sodium chloride solution for $15 \mathrm{~min}$, roasting at 150 to $180^{\circ} \mathrm{C}$ for $30 \mathrm{~min}$ and packaging [2]. In this operation, water absorption and water vapor adsorption and desorption processes are very important, the air-watersolid equilibrium relations in the pistachio nuts determine the optimal conditions of post-harvest physical treatments and storage [3]. The water activity $\left(a_{w}\right)$ of food describes the energy state of water in the food, and hence, its potential to act as a solvent and participate in chemical/ biochemical reactions and growth of microorganisms. It is an important property that is used to predict the stability and safety of food with respect to microbial growth, rates of deteriorative reactions and chemical/physical properties [4]. Sorption isotherms can also be used to design their suitable packaging and storage conditions, and to select proper ingredients for preparation of a formulated intermediate moisture food. However, very limited data are available on sorption isotherms of different pistachio varieties [1]. It is well known that sorption isotherms of foodstuffs are very important for design, modelling and optimization of many processes. Hossain et al. [5] pointed out the importance of those data in drying, aeration, predicting of stability and quality during packaging and storage of food. Moisture sorption isotherms of foods provide critical information that can be used in predicting shelf-life by theoretical calculation. Moisture sorption isotherms can also be used to investigate structural features such as specific surface area, pore volume, pore size distribution, and crystallinity of food products. Many research studies on the sorption isotherms of certain foods, temperature dependence of isotherms, determination of heat of sorption, and mathematical models to represent sorption isotherms have been reported in the literature [6]. Many theoretical, semi-theoretical and empirical sorption models to describe the sorption behavior of foods other substrates have been proposed in the literature [7]. The objectives of this study were to determine the water sorption behavior of the pistachios originated from Gaziantep Region of Turkey at $25^{\circ} \mathrm{C}$ and relative humidities ranging from $10 \%$ to $90 \%$ to propose a mathematical model for prediction of its sorption behaviour as a function of temperature, to evaluate the constants of sorption isotherm models. 


\section{Materials and Methods}

\subsection{Materials}

Roasted pistachio sample was obtained from a local market at Gaziantep. All chemicals used in the preparation of saturated salt solutions were reagent grade (Merck) and water used was deionized distilled water.

\subsection{Determination of Sorption Characteristics of Roasted Pistachio}

A static gravimetric method was used to determine the sorption isotherms at $25{ }^{\circ} \mathrm{C}$ of the roasted pistachio nuts. 10 saturated salt solutions with an average water activity of between 0.10 and 0.90 were prepared for the glass jars which can be closed to prevent air ingress. $0.3 \mathrm{~g}$ pistachio samples were weighed and placed together with two witness samples to each jar. A small amount of toluene was placed in jars with saturated salt solutions with high water activity to prevent microbial spoilage. After the jars were closed tightly, they were placed to an oven set at a constant temperature of $25^{\circ} \mathrm{C}$. Samples were weighed at 1-week intervals. The weighing continued until no difference more than $0.001 \mathrm{~g}$ it was found. The equilibrium moisture content of the samples was determined by drying at $105{ }^{\circ} \mathrm{C}$ for 4 hours. The equilibrium moisture content was plotted against the water activities to form the moisture sorption isotherms. The water activity values of the saturated salt solutions at $25^{\circ} \mathrm{C}$ are given in Table 1.

Table 1. Water activity values of the saturated salt solutions at $25^{\circ} \mathrm{C}$ used in the experiment

\begin{tabular}{cc}
\hline SALT & aw $\left(\mathbf{2 5}^{\circ} \mathbf{C}\right)$ \\
\hline $\mathrm{LiCl}$ & 0,1130 \\
$\mathrm{CH}_{3} \mathrm{COOK}$ & 0,2251 \\
$\mathrm{MgCl}_{2}$ & 0,3278 \\
$\mathrm{~K}_{2} \mathrm{CO}_{3}$ & 0,4316 \\
$\mathrm{Mg}\left(\mathrm{NO}_{3}\right)_{2}$ & 0,5289 \\
$\mathrm{NaBr}$ & 0,5757 \\
$\mathrm{SrCl}_{2}$ & 0,7085 \\
$\mathrm{NaCl}$ & 0,7529 \\
$\mathrm{NH}_{3} \mathrm{SO}_{4}$ & 0,8099 \\
$\mathrm{KCl}$ & 0,8430 \\
\hline
\end{tabular}

The experimental sorption data of all samples at three different temperatures was fitted to sorption equations (with six two-parameters, five three-parameters and one four parameter) shown in Table 2. The parameters of the sorption models were estimated from the experimental results using nonlinear regression analysis (SPSS 13.0 for Windows), which 
minimizes the residual sum of squares. Best-fitting equations were evaluated with the mean relative percentage deviation $(\mathrm{P})$ value and the percentage root mean squares error (RMSE) value. $\mathrm{P}$ value and RMSE value are defined as

$$
\begin{aligned}
& P=\frac{100}{N} \sum_{i=1}^{N} \frac{\mid \text { Mexp-Mcal } \mid}{M \exp } \\
& R M S E=100 \sqrt{\frac{\sum(\text { Mcal-Mexp })^{2} / M \exp }{N}}
\end{aligned}
$$

where Mexp and Mcal are experimental and predicted moisture content values, respectively, and $\mathrm{N}$ is the number of experimental data. A model was considered acceptable if the $\mathrm{P}$ values and RMSE values were below $10 \%$ and $\mathrm{R}^{2}$ values were higher than 0.90 .

Table 2. Equations describing the sorption equilibrium isotherms

\begin{tabular}{cc}
\hline Name of the Equation & Equation \\
\hline BET (Brunauer, Emmet and Teller) [8] & $M=\frac{M 0 c a_{w}}{\left[\left(1-a_{w}\right)+(c-1)\left(1-a_{w}\right) a_{w}\right]}$ \\
GAB (Guggenheim-Andersen-de Boer) [9] & $M=\frac{M 0 C K a_{w}}{\left[\left(1-K a_{w}\right)\left(1-K a_{w}+C K a_{w}\right)\right]}$ \\
Halsey [10] & $a_{w}=\exp \left[-k / M^{n}\right]$ \\
Henderson [11] & $1-a_{w}=\exp \left(-k T M^{n}\right)$ \\
Oswin [12] & $M=k\left(\frac{a_{w}}{1-a_{w}}\right)^{n}$
\end{tabular}

\section{Results and Discussion}

Sorption isotherms are graphs that provide very useful information about the state of the food, determined by plotting the water content of the food at constant temperature versus the water activity of the food. These isotherm graphs are basically as follows; adsorption or desorption isotherms obtained by demonstrating the increased water content of the dry food at constant temperature or the decreasing water content of the wet food against the changing water activity [7]. The sorption data of whole pistachio nuts shows remarkable hysteresis in the multimolecular range and in the cappilary condensation range (between $\mathrm{R}=0.10$ - 0.80). Above this region the difference between adsorption and desorption tends to disappear [3]. Several sorption equations (GAB, BET, Simit, Halsey, Henderson, Iglesias-Chirife, ChungPfost, Oswin, Caurie, and Langmuir et al.) that considered the relationship between water activity, moisture content of food and water binding energy, were developed to represent the sorption isotherms of the foods. However, these equations do not adequately represent all the food. The reason for this is the high heterogeneity of foods in structure and composition. The 
BET equation, which is one of the first sorption equations and widespread employed, can successfully represent the isotherm when the water activity is less than 0.50 [7]. GAB model is about monolayer moisture concept and provides the value of monolayer moisture content of the material, as most other models not have this parameter. The monolayer moisture content $\left(\mathrm{M}_{0}\right)$ indicates the amount of water that is strongly adsorbed to specific sites on the surface of food and is regarded as the moisture content affording the longest time with minimum quality loss at a given temperature [13].

The adsorption isotherm of pistachio at $25^{\circ} \mathrm{C}$ is shown in Fig. 1. The equilibrium moisture content at each $\mathrm{a}_{\mathrm{w}}$ represents the mean value of three replications. The standard deviation of each experimental point ( $\mathrm{kg} / \mathrm{kg}$ dry solids) was within the range of 0.003 to 0.05 .

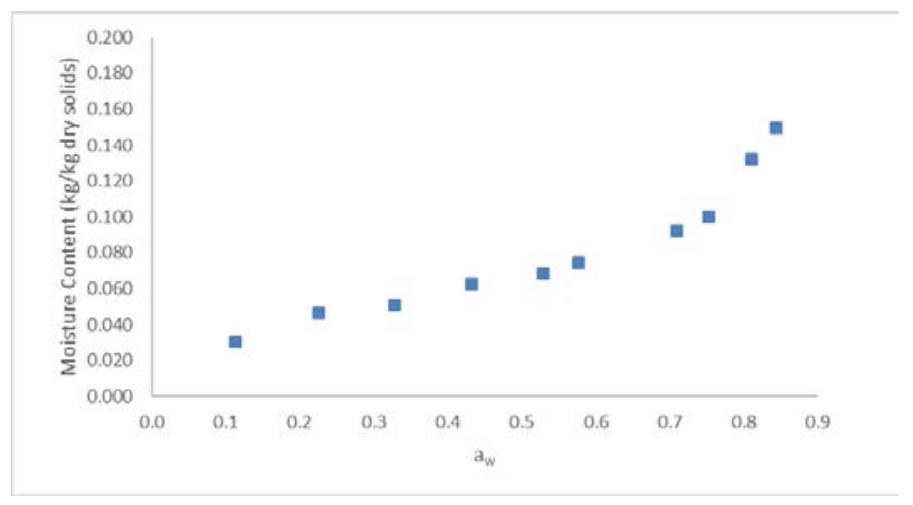

Fig.1 Adsorption isotherms of roasted pistachio $25^{\circ} \mathrm{C}$.

The adsorption isotherms of pistachio showed type II behaviour according to the BET classification, typical of the many sorption isotherms of food [14]. The equilibrium moisture content increases with increasing $\mathrm{a}_{\mathrm{w}}$, at constant temperature. Similar results have been reported in literature for the sorption curve of pistachio [14].

The results of non-linear regression analysis of fitting the sorption equations to the experimental data are presented in Tables 3 . The mean relative percentage deviation $(\mathrm{P})$, the percentage root mean squares error (RMSE) and correlation coefficient $\left(\mathrm{R}^{2}\right)$ values are also given in Tables 3.

The GAB equation (Table 3) gave the best fit to the experimental adsorption data of pistachio for a wide range of water activity (0.10-0.9). This observation is consistent with the results obtained by Maskan [14]. Constant $\mathrm{K}$ value for pistachio in the GAB equation was 0.821 . The value of $\mathrm{K}$ provides a measure of the interactions between the molecules in multilayers with the adsorbent and tends to fall between energy value of the molecules in the monolayer and that of liquid water. The monolayer moisture content $\left(\mathrm{M}_{0}\right)$ helps to define physical and chemical stability of foods since it has a direct influence on lipid oxidation, enzyme activity, 
non-enzymatic browning, flavour preservation and product structure. The BET and GAB monolayer moisture contents for pistachio were $0.038 \mathrm{~kg} / \mathrm{kg}$ dry solid and $0.046 \mathrm{~kg} / \mathrm{kg}$ dry solid, respectively (Tables 3 ). $\mathrm{M}_{0}$ value obtained by the GAB equation was higher than those obtained by the BET model. Moreover, the Oswin, Halsey and Henderson equations (Table 3) gave a satisfactory prediction of the adsorption equilibrium moisture content of pistachio.

Table 3. Estimated parameters and P (\%), RMSE (\%), $R^{2}$ values of the sorption equations

\begin{tabular}{|c|c|c|}
\hline Model & Parameters & $\begin{array}{c}\text { Temperature } \\
25\left({ }^{\circ} \mathrm{C}\right)\end{array}$ \\
\hline \multirow{5}{*}{$\mathrm{BET}^{\mathrm{a}}$} & $\mathrm{M}_{0}$ & 0.038 \\
\hline & $\mathrm{C}$ & 22.79 \\
\hline & P (\%) & 4.439 \\
\hline & RMSE (\%) & 0.028 \\
\hline & $\mathrm{R}^{2}$ & 0.961 \\
\hline \multirow{5}{*}{ GAB } & $\mathrm{M}_{0}$ & 0.046 \\
\hline & $\mathrm{C}$ & 8.457 \\
\hline & K & 0.821 \\
\hline & P (\%) & 5.924 \\
\hline & RMSE (\%) & 0.456 \\
\hline \multirow{6}{*}{ Halsey } & $\mathrm{R}^{2}$ & 0.984 \\
\hline & $\mathrm{k}$ & 0.005 \\
\hline & $\mathrm{n}$ & 1.834 \\
\hline & P (\%) & 9.333 \\
\hline & RMSE (\%) & 2.853 \\
\hline & $\mathrm{R}^{2}$ & 0.986 \\
\hline \multirow{4}{*}{ Henderson } & $\mathrm{k}$ & 0.208 \\
\hline & $\mathrm{n}$ & 1.685 \\
\hline & P (\%) & 10.99 \\
\hline & RMSE (\%) & 4.616 \\
\hline \multirow{6}{*}{ Oswin } & $\mathrm{R}^{2}$ & 0.963 \\
\hline & $\mathrm{k}$ & 0.068 \\
\hline & $\mathrm{n}$ & 0.441 \\
\hline & P (\%) & 6.714 \\
\hline & RMSE (\%) & 0.573 \\
\hline & $\mathrm{R}^{2}$ & 0.975 \\
\hline
\end{tabular}

As seen in Table 3, the BET equation gives the lowest P \% and RMSE \% value in the water activity range 0.11-0.5. Furthermore, the GAB equation representing multi-layer adsorption gave the best fit to the experimental data for pistachio. The experimental adsorption data and the predicted values obtained from different sorption models at $25^{\circ} \mathrm{C}$ are shown in Fig. 2 .

It should be noted that, the goodness of fit of any sorption model to the experimental data shows only a mathematical quality and not the nature of the sorption process [15]. 


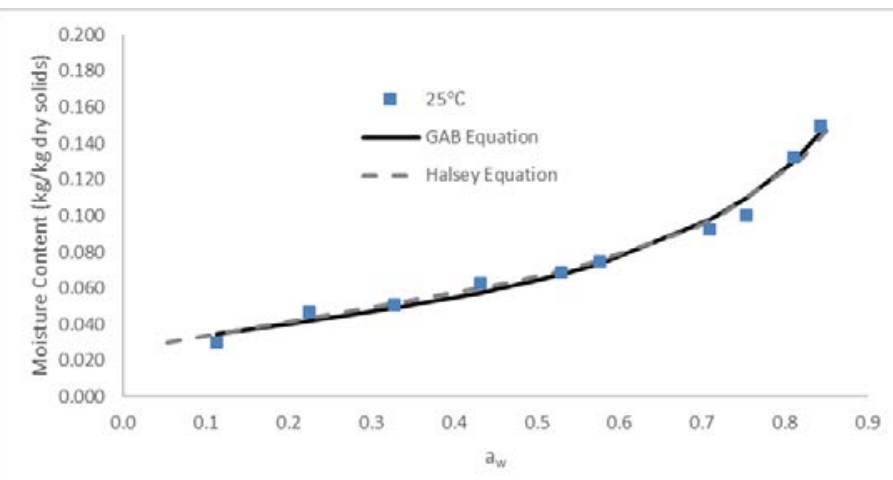

Figure 2. Comparison of experimental and predicted adsorption equilibrium moisture contents of pistachio at $25^{\circ} \mathrm{C}$.

\section{Conclusions}

The equilibrium moisture content of pistachio increased with increasing water activity at constant temperature. Among the sorption models tested, the GAB equation was recommended for characterising the adsorption behaviour of pistachio in the water activity range of 0.11-0.87. The adsorption data were also expressed by the Halsey equations in the wide range of water activity and by the BET equation in the range of water activity 0.1-0.5.

\section{References}

[1] Tavakolipour, H. Postharvest Operations Of Pistachio Nuts; Journal Food Science Technology India, 2015, 52(2) ,1124-1130.

[2] Yanniotis, S.; Zarmboutis, I. Water Sorption Isotherms Of Pistachio Nuts; LebensmittelWissenschaft Und-Technologie 1996, 29, 372-375.

[3] Maskan, M.; Karatas, S. Sorption Characteristics Of Whole Pistachio Nuts; Drying Technology 1997, 15 (3\&4), 1119-1139.

[4] Aktas, T.; Polat, R. Changes In The Drying Characteristics And Water Activity Values Of Selected Pistachio Cultivars During Hot Air Drying Journal of Food Process Engineering 2007, 30, 607-624.

[5] Furmaniak, S.; Terzyk, A. P.; Gauden, P.A.; Gerhard, R.; Applicability Of The Generalised D’Arcy And Watt Model To Description Of Water Sorption On Pineapple And Other Foodstuffs; Journal of Food Engineering 2007, 79, 718-723.

[6] Koc, B.; Yilmazer, S. M.; Balkir, P.; Ertekin, K. F.; Moisture Sorption Isotherms And Storage Stability Of Spray-Dried Yogurt Powder; Drying Technology 2010, 28, 816822. 
[7] Erbas, M.; Candal, C.; Kılıc, O.; Mutlu, C.; Determination And Solution Of Moisture Sorption Isotherms Of Foods; Resarch Gate- GIDA 2016, 41 (3),171-178.

[8] Brunauer, S.; Emmett, P.H.; Teller, E. Adsorption of gases in multimolecular layer. Journal of American Chemists Society 1938, 60: 309-319.

[9] Van den Berg, C. Development of B.E.T. like models for sorption of water of foods; theory and relevance. In Properties of Water in Foods. Eds. D. Simatos and J. L. Multon. Martinus Nijhoft, Dordrecht, p. 119, 1985.

[10] Halsey, G. Physical adsorption on non-uniform surfaces. Journal of Chemistry and Physics 1948, 16: 931-937.

[11] Henderson, S.M. A basic concept of equilibrium moisture. Agricultural Engineering 1952, 33: 29-32.

[12] Oswin, C.R. The kinetics of packing life. III. The isotherm. Journal of Chemical Industry 1946, 65: 419-423.

[13] Wani, S. A.;Kumar, P.; Moisture Sorption Isotherms And Evaluation Of Quality Changes In Extruded Snacks During Storage; LWT - Food Science and Technology 2016,74, 448-455

[14] Maskan, M.; Gogus, F.; The Fitting Of Varios Models to Water Sorption Isotherms Of Oistachio Nut Paste; Journal Of Food Engineering 1997, 33, 227-237.

[15] Kaymak-Ertekin, F.; Gedik, A. Sorption isotherms and isosteric heat of sorption for rapes, apricots, apples and potatoes. Lebensmittel- Wissenschaft und Technologie 2004, 37: 429-438. 